\title{
Physiological response to a breed evaluation field test in Icelandic horses
}

\author{
G. J. Stefánsdóttir ${ }^{1,2 \dagger}$, S. Ragnarsson ${ }^{1}$, V. Gunnarsson ${ }^{1}$ and A. Jansson ${ }^{1,2}$ \\ ${ }^{1}$ Department of Equine Science, Hólar University College, 551 Sauðárkrókur, Iceland; ${ }^{2}$ Department of Animal Nutrition and Management, Swedish University of \\ Agricultural Sciences, P.O. Box 7024, 75007 Uppsala, Sweden
}

(Received 26 June 2013; Accepted 28 November 2013; First published online 6 January 2014)

This study examined the response in terms of heart rate (HR), respiratory rate (RR), haematocrit (Htc), rectal temperature (RT), and some plasma variables in Icelandic horses of different sexes and ages performing the riding assessment in a breed evaluation field test (BEFT). The study was conducted in Iceland on 266 horses (180 mares and 86 stallions, divided into four age groups; 4, 5, 6 and $\geqslant 7$ years old). $R T$ and $R R$ were recorded and blood samples were taken before the warm-up and after the riding assessment. Horse $H R$, velocity and distance were recorded during the warm-up, the riding assessment and a 5-min recovery period. The distance covered in the BEFT was $2.9 \pm 0.4 \mathrm{~km}$ (range: 1.8 to $3.8 \mathrm{~km}, \mathrm{n}=248$ ), the duration was 9:37 1:22 min:s (range: 5:07 to 15:32 min:s, $\mathrm{n}=260$ ) and the average speed was $17.8 \pm 1.4 \mathrm{~km} / \mathrm{h}$ (range: 13.2 to $21.3 \mathrm{~km} / \mathrm{h}, \mathrm{n}=248$ ). Average HR was $184 \pm 13$ b.p.m. (range: 138 to 210 b.p.m., $\mathrm{n}=102$ ) and peak HR $224 \pm 9$ b.p.m. (range: 195 to 238 b.p.m., $\mathrm{n}=102$ ), and $36 \%$ of the BEFT was performed at $H R \geqslant 200$ b.p.m. Post-exercise plasma lactate concentration (Lac) was $18.0 \pm 6.5 \mathrm{mmol} / \mathrm{l}$ (range: 2.1 to $34.4 \mathrm{mmol} / \mathrm{l}$, $\mathrm{n}=266)$, and there was an increase in total plasma protein, plasma creatine kinase and aspartate amino transferase concentration, as well as RR, RT and Htc. Stallions covered a longer total distance (in the warm-up and BEFT) $(\mathrm{P}<0.05)$, at a faster speed during BEFT $(\mathrm{P}<0.001)$ than mares and had higher Htc and lower HR and post-exercise Lac values. There were few effects of age, but the 4- and 5-year-old horses had lower Htc than older horses and 4-year-old horses had higher post-exercise RR than older horses, although they were ridden for a shorter distance, shorter duration and at lower peak velocity $(\mathrm{P}<0.1)$. The results showed that the riding assessment in the BEFT is a high-intensity exercise. The results also showed that aerobic fitness was higher in stallions and that age had a limited effect on the physiological response. It is suggested that these results should be used as a guide for the development of training programmes and fitness tests in Icelandic horses that would improve both performance and welfare of the horse.

Keywords: exercise physiology, hematological parameters, lactate, heart rate, Icelandic horse

\section{Implications}

The Icelandic horse breed is widespread and its popularity is increasing as a leisure and sport horse for gait competitions. However, knowledge is lacking on the physiological response of Icelandic horses to exercise and competitions. Therefore, it is an animal welfare issue to generate such knowledge, so that training programmes and competition content can be adjusted to support the general welfare of the breed.

\section{Introduction}

The Icelandic horse is a purebred gaited riding horse originating from Iceland (International Federation of Icelandic Horse

\footnotetext{
† E-mail: gudrunst@holar.is
}

Associations (FEIF), 2002), but located in 33 countries outside Iceland and bred in 18 countries (WorldFengur, 2013). The breed evaluation system and the studbook WorldFengur (2013) are also international (FEIF, 2002). The official breeding goal includes 15 traits (eight conformation and seven riding ability traits) that are assessed individually at breeding shows, hereafter referred to as the breed evaluation field test (BEFT), which is standard for all countries (FEIF, 2002). In recent years (2008 to 2012), 1700 to 2800 horses attended a BEFT every year, of which 1000 to 1800 were in Iceland (FEIF, 2013). For comparison, the number of live foals registered in FEIF countries annually in 2008 to 2012 ranged from 10559 to 14866 , of which 4861 to 7399 were in Iceland (WorldFengur, 2013).

The BEFT consists of three parts: (1) objective body measurements, (2) judging of conformational traits and 
(3) riding abilities. Scores for conformation and riding abilities are weighed to give the final total score. Riding abilities (performance in walk, tölt, trot, flying pace (pace) and canter/gallop, as well as spirit and general impression) account for $60 \%$ of the total score and conformation for $40 \%$ (FEIF, 2002). It is known that stallions obtain higher total scores than mares and that total score increases with age from 4 to 6 years and older (Árnason, 1984). This implies that fitness and also physiological characteristics related to age and sex could be important for performance. It is known from other breeds that performance is higher in stallions than in mares (Buttram et al., 1988; Persson, 1997) and increases with age, at least to a certain limit (Seeherman and Morris, 1991) and that sex, age (Ronéus et al., 1991; Ronéus, 1993) and training (Ronéus et al., 1992) influence, for example, muscle fibre composition and also blood volume and haematocrit (Htc) (Persson et al., 1996).

To the best of our knowledge, no published data are available on the physiological response of Icelandic horses to a BEFT. In fact, the physiological responses of this breed to exercise have not been assessed, except in a few pilot studies (unpublished results). However, speed observations from competitions (WorldFengur, 2013) and heart rate (HR) and blood lactate responses from the pilot studies indicate that Icelandic horses are subjected to high workloads. Therefore, the aim of this study was to describe the response in terms of heart and respiratory rate (RR), Htc, rectal temperature (RT), and some plasma variables in stallions and mares of different ages performing a BEFT. Our starting hypotheses were that the BEFT is a high-intensity exercise and that some physiological responses could be affected by sex and age.

\section{Material and methods}

The study was approved by the National Animal Research Committee of Iceland. The study was conducted at BEFT in Hella in southern Iceland on 30 May to 2 June and 6 to 9 June 2011. Owners and trainers were informed that participation in the study was voluntary.

\section{BEFT and design of the study}

The riding abilities of a horse are judged in two separate assessments. In the first and main assessment, the horse is expected to show all its gaits, but exactly how this is done is decided by the rider. The horse is ridden alone on a straight field track ( 250 to $300 \mathrm{~m}$ long, 4 to $6 \mathrm{~m}$ wide) and $200 \mathrm{~m}$ of the track is used for judging and $50 \mathrm{~m}$ at each end to turn around. The horse has to be ridden along the track a minimum of six times and a maximum of 10 times, that is, three to five times in each direction (FEIF, 2002). The second assessment is voluntary and is carried out if the rider/trainer/owner would like to try to improve the scores from the first assessment. In the present study, only the results from the first assessment were included.

$A$ horse must be at least 4 years old in the calendar year to be judged for riding abilities in BEFT. Stallions and mares are shown in separate sex and age classes $(4,5,6$ and $\geqslant 7$ years old) and geldings are shown in one group irrespective of age (FEIF, 2002), as very few are judged annually (WorldFengur, 2013). Only mares and stallions were included in the present study. According to the judging scale used in a BEFT, each trait is scored within the range 5.0 to 10.0 , with 0.5 increments. A score of 5.0 is given if a gait is not shown and 10.0 is given for an excellent trait (FEIF, 2002). Three internationally accepted judges generally work in a committee and give a joint score for each trait (FEIF, 2002). During the present study six judges worked, three at a time. Immediately after a horse has finished the riding assessment, there is also an obligatory shoe and health check (legs and mouth), which lasts for about 1 to $2 \mathrm{~min}$.

\section{Horses}

In total, 396 horses were shown at the BEFT and the study included 266 of these, 86 stallions and 180 mares, leaving 130 in a 'non-study' group. The horses were mainly fed roughage $5.7 \pm 1.5 \mathrm{~kg}$ (range: 0 to $12 \mathrm{~kg}, n=254$ ) and some (at least $10 \%$ ) were also grazed $(0.5$ to $6.0 \mathrm{~h} /$ day), whereas one horse was grazed only. Most horses $(68 \%)$ were given some concentrates $(1.1 \pm 0.5 \mathrm{~kg}$, range: 0.2 to $4 \mathrm{~kg}, n=182)$. The inclusion criteria were that the owners/trainers were willing to take part, and that the horses were judged for both conformation and riding abilities and had completed both parts of the BEFT. One of the horses in the study was later disqualified and did not get a score because of deviation from the rules of legal shoes.

\section{Data collection}

Before the riding assessment, the BW of each horse and rider and the weight of a spot sample of saddles (23 saddles and blankets) were recorded using an electronic livestock scale (Smartscale 300; Gallagher, Hamilton, New Zealand). The ratio of rider BW (riding tack not included) to horse BW was calculated (BWR) and used as a variable in the statistical analyses. The riders answered a questionnaire about the horse regarding name, age, feeding, travel time to the showground and the level of preparation for the BEFT (scale 1 to $10,1=$ badly and $10=$ very well prepared). The horses were given a body condition score (BCS) according to the specific BCS-scale devised for Icelandic horses (scale 1 to 5; Stefánsdóttir and Björnsdóttir, 2001).

RT (digital thermometer; Disney, Hartmann, Heidenheim, Germany) was measured and RR was recorded by counting breaths both before the horses were warmed up before the riding assessment and within 5 min after the riding assessment. Blood samples were also taken from the jugular vein by Vacutainer in chilled lithium heparinised tubes $\left(9 \mathrm{ml}\right.$, Vacuette ${ }^{\circledR}$; Greine-Bio-One, Kremsmuenster, Austria) before the warm-up and the riding assessment and within 5 min after the horse left the track after performing the riding assessment. The same person recorded RT and RR and collected the blood samples.

During the warm-up and riding assessment, and for a 5-min recovery period after the assessment HR (Polar HR Monitor RS800CX and belt with Polar Equine T56H transmitter W.I.N.D., Kempele, Finland), velocity and distance covered (Polar G3 GPS sensor, Kempele, Finland) were 
recorded. According to the manufacturer, the accuracy of distance measurements is $\pm 2 \%$ and that of velocity measurements is $\pm 2 \mathrm{~km} / \mathrm{h}$. The HR monitors were set to record in $1 \mathrm{~s}$ mode. All horses were videotaped during the riding assessment, using a digital HD video-camera recorder (Sony HDR CX360VE, Tokyo, Japan). All watches used in the study (on HR monitors, the video camera and watches used to record times) were synchronised and the video recordings were used to check and synchronise the start and end time of the riding assessment. The riding track was labelled with bars every $50 \mathrm{~m}$ for $300 \mathrm{~m}$. Scores from the riding assessment and information on wither height (WH) were obtained from the official studbook (WorldFengur, 2013).

The weather at the showground was recorded every $5 \mathrm{~min}$ (two to four observations per horse) by an automatic weather station (Art. no. 36-3242, Model WH-1080; Clas Ohlson, Insjön, Sweden). The ambient temperature at the track was $10.7 \pm 2.0^{\circ} \mathrm{C}$ (range: 9.0 to $14.1^{\circ} \mathrm{C}$ ), the relative humidity $38 \pm 14 \%$ (range: $24 \%$ to $60 \%$ ), the wind speed $5.6 \pm 2.3 \mathrm{~m} / \mathrm{s}$ (range: 3.5 to $9.8 \mathrm{~m} / \mathrm{s}$ ) and average strongest wind speed $7.6 \pm 2.9 \mathrm{~m} / \mathrm{s}$ (range: 5.0 to $12.9 \mathrm{~m} / \mathrm{s}$ ).

\section{Blood analysis}

Blood samples were kept chilled and Htc and haemoglobin $(\mathrm{Hb})$ were analysed within $30 \mathrm{~min}$. Htc was analysed using non-heparinised capillary tubes, centrifuged at $18840 \times \mathbf{g}$ (Sigma 1-15; Laborzentrifugen GmbH, Osterode am Harz, Germany) for $6 \mathrm{~min}$. Triple measurements were performed and a mean value was used for the statistical analyses. $\mathrm{Hb}$ concentration was analysed using a Hemocue POC analyser (Helsingborg, Sweden). Plasma was separated by centrifugation (15 min, $520 \times \mathbf{g}$, Hettich, Tuttlingen, Germany) and stored at $-18^{\circ} \mathrm{C}$ until analysis of lactate, creatine kinase (CK), aspartate amino transferase (AST) and total plasma protein concentration (TPP). Plasma lactate concentration (Lac) was analysed after $\sim 4$ months using an enzymatic (L-lactate dehydrogenase and glutamate-pyruvate transaminase) and spectrophotometric method (Boehringer Mannheim/R-Biopharm, Darmstadt, Germany) with a CV of $2.3 \%$ according to the manufacturer. All duplicates showing variation $>10 \%$ were re-analysed until the variation was $<10 \%$. The CV of the plasma lactate analyses was $3.3 \%$. CK and AST were analysed after $\sim 4$ months using an enzymatic method (spectrophotometer, Architect $\mathrm{c4000}$, Abbott Park, IL, USA). TPP was analysed after $\sim 12$ months using a refractometer (Atago, Tokyo, Japan).

\section{Data handling}

All HR recordings were transported using an infrared USB Adapter (IrDA, Kempele, Finland) to the software Polar Pro Trainer 5 Equine Edition (Kempele, Finland) and then transferred to Microsoft Excel 2010 for further analysis. Only HR recordings where a minimum of $80 \%$ of the recording for the whole riding assessment was considered reliable were used, which resulted in 102 observations. On average, $6 \pm 6 \%$ ( $34 \pm 34$ s/horse) of the recordings from the 102 horses were excluded from the analysis.

\section{Statistical analysis}

Means and standard deviations were calculated for descriptive data and Pearson's correlations were performed in SAS (Statistical Analysis Systems package 9.2, Cary NC, USA). ANOVA was performed using Proc GLM (model 1 and 2) and Proc MIXED (model 3 and 4) in SAS. The results are expressed as least square means (LS Means) with their root mean square error (RMSE). For comparison, the Tukey test was used and level of statistical significance was set to $P<0.05$.

The BCS, WH, BW and level of preparation were analysed using model (1): $Y_{i j}=\mu+\alpha_{i}+\beta_{j}+e_{i j,}$ where $Y_{i j}$ is the observation/parameter, $\mu$ the mean value, $\alpha_{i}$ the fixed effect of sex, $\beta_{j}$ the fixed effect of age group and $e_{i j}$ the residuals; $e_{i j} \sim\left(0, \delta^{2}\right)$.

The before and after samples and whether the two groups of horses (study and non-study) differed in total score for riding abilities were analysed using model (2): $Y_{i j k}=\mu+$ $\alpha_{i}+\beta_{j}+\varepsilon_{k}+e_{i j k,}$ where $Y_{i j k}$ is the observation/parameter, $\mu$ the mean value, $\alpha_{i}$ the fixed effect of sex, $\beta_{i}$ the fixed effect of age group, $\varepsilon_{k}$ the fixed effect of sample/group of horse and $e_{i j k}$ the residuals; $e_{i j k} \sim\left(0, \delta^{2}\right)$.

The variables distance, speed and duration of warm-up, and the BEFT were analysed using model (3): $Y_{i j k r}=\mu+$ $\alpha_{i}+\beta_{j}+\varepsilon_{k}+a_{r}+e_{i j k r}$ where $Y_{i j k r}$ is the observation/parameter, $\mu$ the mean value, $\alpha_{i}$ the fixed effect of sex, $\beta_{j}$ the fixed effect of age group, $\varepsilon_{k}$ the fixed effect of whether a horse was scored for pace or not, $a_{r}$ the random effect of the rider and $e_{i j k r}$ the residuals; $e_{i j k r} \sim\left(0, \delta^{2}\right)$. Interactions between fixed factors were tested in the model, but no effect was found for any of the variables tested. The random factor 'rider' accounted for $5 \%$ to $46 \%$ of the random variation in the models for distance, duration and speed, that is, the variation that was not explained by the fixed factors.

The physiological responses (overall effect) to the BEFT and the total score for riding abilities were analysed using model (4): $Y_{i j k l m n r}=\mu+\alpha_{i}+\beta_{j}+\varepsilon_{k}+\gamma_{I}+\eta_{m}+\tau_{n}+a_{r}+$ $e_{i j k l m n n}$ where $Y_{i j k l m n r}$ is the observation, $\mu$ the mean value, $\alpha_{i}$ the fixed effect of sex, $\beta_{j}$ the fixed effect of age group, $\varepsilon_{k}$ the fixed effect of whether a horse was scored for pace or not, $\gamma_{I}$ the average velocity of a horse in the BEFT as a continuous variable, $\eta_{m}$ the distance ridden in the BEFT as a continuous variable, $\tau_{n}$ the BWR as a continuous variable, $a_{r}$ the random effect of the rider and $e_{i j k l m r}$ the residuals; $e_{i j k l m n r} \sim\left(0, \delta^{2}\right)$. The random factor 'rider' accounted for $0 \%$ to $18 \%$ of the random variation in the models for physiological responses to the BEFT and for total score for riding abilities, that is, the variation that was not described by the fixed factors.

\section{Results}

Description of horses, riders and riding tack included in the study

The mean travel time to the BEFT was $31 \pm 31$ min (range: 3 to $180 \mathrm{~min}$ ) but two horses had travelled for $6 \mathrm{~h}$ on the previous day. 
The scores for riding abilities of the horses participating in the study $(n=265)$ and the non-study horses $(n=130)$ were not different $(P>0.05)$ for the whole group $(7.69 \mathrm{~V}$. 7.72, RMSE $=0.32$ ). In addition, there were no differences between the age groups within the studied group and non-studied group (4-year-olds: 7.52 v. 7.41, RMSE $=0.29$, 5-year-olds: 7.71 v. 7.71, RMSE $=0.27,6$-year-olds: $7.79 \mathrm{v}$. 7.89, RMSE $=0.33, \geqslant 7$-year-olds: 7.79 v. $7.85, \mathrm{RMSE}=0.36$ ) or the sex groups (stallions: 7.82 v. $7.79, \mathrm{RMSE}=0.34$; mares: 7.59 v. 7.66, RMSE $=0.30$ ). The average age of the horses was $5.9 \pm 1.4$ year (range: 4 to 11 years, $n=266$; Table 1). The WH was $141.0 \pm 2.7 \mathrm{~cm}$ (range: 134.0 to 149.0 $\mathrm{cm}, n=266$ ), and was greater in stallions than in mares (141.9 v. $140.4 \mathrm{~cm}, \mathrm{RMSE}=2.6, P<0.001)$, but did not differ $(P>0.05)$ between age groups. The BW was $339 \pm 19 \mathrm{~kg}$ (range: 289 to $397 \mathrm{~kg}, n=264$ ) and was not affected by sex (stallions: $340 \mathrm{v}$. mares: $338 \mathrm{~kg}, \mathrm{RMSE}=19, P>0.05$ ). However, 4- and 5-year-old horses were lighter than horses $\geqslant 7$ years old $(333,335$ and $346 \mathrm{~kg}$, respectively, $\mathrm{RMSE}=19$, $P<0.01$ ), whereas the BW of 6-year-olds ( $342 \mathrm{~kg}, P>0.05$ ) did not differ from that of the other age groups. The BCS

Table 1 Number of horses participating in the study, divided into sex and age group

\begin{tabular}{lccccr}
\hline \hline & \multicolumn{5}{c}{ Age group } \\
\cline { 2 - 6 } & 4 years & 5 years & 6 years & 7 years and older & Total \\
\hline Mares & 19 & 55 & 55 & 51 & 180 \\
Stallions & 18 & 28 & 19 & 21 & 86 \\
Total & 37 & 83 & 74 & 72 & 266 \\
\hline \hline
\end{tabular}

of stallions was lower than that of mares $(2.9 \mathrm{v}$. 3.1, RMSE $=0.3, P<0.001)$ and did not differ $(P>0.05)$ between age groups.

The study involved 69 riders, who each rode 1 to 29 horses. Five riders rode $\geqslant 10$ horses and 13 riders $\geqslant 5$ horses, whereas 56 riders rode 1 to 4 horses. Rider BW was $83 \pm 11 \mathrm{~kg}$ (range: 59 to $112 \mathrm{~kg}, n=67$ ) and weight of saddle and blanket was $8.7 \pm 1.0 \mathrm{~kg}$ (range: $6.8-10.4 \mathrm{~kg}, n=23$ ). According to the riders, there was a wide range in the level of preparation ( $2 \%$ scores 1.0 to $3.9,36 \%$ scores 4.0 to 6.9 and $62 \%$ scores 7.0 to $10.0, n=248$ ).

Duration, distance, and speed of the warm-up and BEFT Duration, distance, and speed of the warm-up were not affected $(P>0.05)$ by sex, age group or whether the horse showed pace or not in the BEFT (Table 2). The distance of the BEFT was $2.9 \pm 0.4 \mathrm{~km}$ (range: 1.8 to $3.8 \mathrm{~km}, n=248$ ), the duration was 9:37 $\pm 1: 22$ min:s (range: 5:07 to $15: 32 \mathrm{~min}: s$, $n=260$ ) and the average speed during the BEFT was $17.8 \pm 1.4 \mathrm{~km} / \mathrm{h}$ (range: 13.2 to $21.3 \mathrm{~km} / \mathrm{h}, n=248$ ). Most horses $(41 \%)$ were ridden $\geqslant 3.0 \mathrm{~km}$, whereas $20 \%$ were ridden $<2.5 \mathrm{~km}$ and $39 \%$ were ridden 2.5 to $<3.0 \mathrm{~km}$.

Stallions covered a longer distance in the BEFT than mares $(P<0.05)$ and horses that showed pace (score $\geqslant 5.5$ for pace) covered a longer distance than those that did not (score $=$ 5.0 for pace) (2.9 v. $2.8 \mathrm{~km}, \mathrm{RMSE}=0.3, P<0.05$; Table 2). Stallions were ridden at a faster speed than mares $(P<0.001)$ and horses awarded a score for pace were faster than horses that received no score for pace $(18.0 \mathrm{v} .17 .5 \mathrm{~km} / \mathrm{h}$, RMSE $=1.1, P<0.01$; Table 2). Stallions covered a longer distance in total (in warm-up and BEFT) than mares $(P<0.05$; Table 2).

Table 2 Duration, distance, and speed of stallions and mares in warm-up and the breed evaluation field test (BEFT) ${ }^{1}$ and effects of sex, age group (age: 4, 5, 6 and $\geqslant 7$ years) and whether flying pace (Pace) was shown or not

\begin{tabular}{|c|c|c|c|c|c|c|c|c|c|c|c|c|}
\hline & \multicolumn{4}{|c|}{ Stallions } & \multicolumn{4}{|c|}{ Mares } & \multirow[b]{2}{*}{ RMSE } & \multicolumn{3}{|c|}{$P$-values } \\
\hline & $n$ & Mean & Min & Max & $n$ & Mean & Min & Max & & Sex & Age & Pace \\
\hline \multicolumn{13}{|l|}{ Warm-up } \\
\hline Distance (km) & 85 & 2.2 & 0.3 & 4.7 & 164 & 2.0 & 0.2 & 6.3 & 0.8 & 0.070 & 0.542 & 0.654 \\
\hline Duration (min:s) & 85 & $19: 06$ & 03:05 & 49:02 & 174 & $18: 48$ & 02:00 & $50: 28$ & 08:47 & 0.806 & 0.786 & 0.088 \\
\hline Average speed in warm-up $(\mathrm{km} / \mathrm{h})^{2}$ & 85 & 7.2 & 2.3 & 16.8 & 164 & 6.9 & 2.0 & 13.2 & 2.3 & 0.356 & 0.838 & 0.175 \\
\hline Average speed, moving in warm-up $(\mathrm{km} / \mathrm{h})^{3}$ & 85 & 10.8 & 5.7 & 19.7 & 164 & 10.8 & 5.8 & 17.0 & 2.1 & 0.886 & 0.949 & 0.459 \\
\hline Peak speed in warm-up & 85 & 23.5 & 14.9 & 38.5 & 164 & 23.0 & 15.4 & 38.7 & 2.9 & 0.217 & 0.440 & 0.934 \\
\hline \multicolumn{13}{|l|}{ BEFT } \\
\hline Distance $(\mathrm{km})$ & 85 & 2.9 & 1.8 & 3.6 & 162 & 2.8 & 1.8 & 3.8 & 0.3 & 0.027 & 0.064 & 0.013 \\
\hline Duration (min:s) & 85 & 09:40 & 05:17 & $15: 32$ & 174 & 09:33 & 06:10 & $13: 27$ & 01:07 & 0.472 & 0.050 & 0.717 \\
\hline Average speed $(\mathrm{km} / \mathrm{h})$ & 85 & 18.0 & 13.2 & 21.1 & 162 & 17.4 & 13.4 & 21.3 & 1.1 & 0.001 & 0.212 & 0.003 \\
\hline Peak speed $(\mathrm{km} / \mathrm{h})$ & 85 & 42.1 & 32.0 & 56.8 & 162 & 42.0 & 33.5 & 52.2 & 3.3 & 0.826 & 0.068 & 0.718 \\
\hline \multicolumn{13}{|l|}{ Total for warm-up and BEFT } \\
\hline Distance $(\mathrm{km})$ & 85 & 5.1 & 3.5 & 7.3 & 162 & 4.8 & 2.9 & 9.4 & 0.8 & 0.014 & 0.288 & 0.537 \\
\hline Duration (min:s) & 85 & $28: 36$ & $12: 04$ & $60: 07$ & 174 & $28: 13$ & $11: 24$ & $60: 40$ & 08:50 & 0.752 & 0.700 & 0.084 \\
\hline
\end{tabular}

${ }^{1}$ Values presented as least square means (mean) and root mean standard error (RMSE) and minimum (min) and maximum (max) values.

${ }^{2}$ The average speed in the complete duration of warm-up.

${ }^{3}$ The average speed in the duration of warm-up after excluding the part when horses and riders were standing still and waiting to start the riding assessment. 
Physiological response in Icelandic horses

Table 3 Physiological responses in stallions and mares before warm-up and after the breed evaluation field test (BEFT) ${ }^{1}$ and effects of sex, age group (age; 4, 5, 6 and $\geqslant 7$ years), whether flying pace (Pace) was shown or not, distance (Dist.), velocity (Vel.) and BWR2

\begin{tabular}{|c|c|c|c|c|c|c|c|c|c|c|c|c|c|c|c|}
\hline & \multicolumn{4}{|c|}{ Stallions } & \multicolumn{4}{|c|}{ Mares } & \multirow[b]{2}{*}{ RMSE } & \multicolumn{6}{|c|}{$P$-values } \\
\hline & $n$ & Mean & Min & Max & $n$ & Mean & Min & Max & & Sex & Age & Pace & Dist. & Vel. & BWR \\
\hline$R$ bef & 84 & 29 & 16 & 72 & 158 & 30 & 12 & 76 & 1 & 0.983 & 4 & 0.548 & 0.236 & 0.311 & 0.9 \\
\hline RR after (breaths & 84 & 103 & 40 & 160 & 159 & 103 & 12 & 168 & 28 & 0.915 & 0.015 & 0.363 & 0.415 & 0.001 & 0.39 \\
\hline RT before $\left({ }^{\circ} \mathrm{C}\right)$ & 84 & 37.8 & 36.7 & 38.5 & 158 & 37.8 & 36.9 & 38.6 & 0.3 & 0.770 & 0.419 & 0.979 & 0.527 & 0.546 & 0.41 \\
\hline $\mathrm{RT}$ after $\left({ }^{\circ} \mathrm{C}\right)$ & 84 & 39.4 & 38.0 & 40.9 & 158 & 39.6 & 38.4 & 41.1 & 0.5 & 0.041 & 0.796 & 0.566 & 0.015 & 0.105 & 0.410 \\
\hline RT change $\left({ }^{\circ} \mathrm{C}\right)$ & 84 & 1.7 & 0.4 & 3.4 & 158 & 1.8 & 0.5 & 3.7 & 0.5 & 0.067 & 0.510 & 0.512 & 0.029 & 0.060 & 0.144 \\
\hline Haematocrit befo & 84 & 39 & 27 & 50 & 159 & 34 & 25 & 42 & 3 & $<0.001$ & 0.189 & 0.327 & 0.830 & 0.452 & 0.086 \\
\hline Haem & 84 & 49 & 41 & 55 & 159 & 43 & 36 & 50 & 2 & $<0.001$ & $<0.001$ & 0.275 & & & 0.085 \\
\hline before $(g / l)$ & 83 & 140 & 110 & 197 & 149 & 122 & 95 & 151 & 13 & $<0.001$ & 0.243 & 0.839 & 0.834 & 0.181 & 0.030 \\
\hline after ( $g / l)$ & 84 & 176 & 150 & 202 & 159 & 157 & 132 & 194 & 10 & $<0.001$ & 0.002 & 0.941 & 0.339 & 0.215 & 0.002 \\
\hline before $(g / l)$ & 84 & 61 & 54 & 70 & 157 & 59 & 49 & 74 & 4 & $<0.001$ & 0.314 & 0.798 & 0.692 & 0.215 & 0.966 \\
\hline TPP concentr & 79 & 65 & 58 & 76 & 149 & 63 & 52 & 80 & 4 & $<0.001$ & 0.088 & 0.219 & 0.975 & 0.243 & 0.877 \\
\hline CK concentra & 84 & 239 & 117 & 1633 & 159 & 237 & 105 & 1913 & 155 & 0.946 & 0.143 & 0.990 & 0.167 & 0.526 & 0.437 \\
\hline fter (U/l) & 84 & 298 & 135 & 2008 & 159 & 295 & 103 & 2162 & 221 & 0.941 & 0.113 & 0.533 & 0.005 & 0.095 & 0.801 \\
\hline AST concentration before (U/l) & 84 & 349 & 195 & 625 & 159 & 354 & 158 & 894 & 96 & 0.686 & 0.890 & 0.614 & 0.188 & 0.001 & 0.942 \\
\hline AST concentration after (U/l) & 84 & 383 & 229 & 643 & 159 & 378 & 124 & 928 & 102 & 0.739 & 0.838 & 0.860 & 0.154 & 0.005 & 0.92 \\
\hline Lac CC & 84 & 13.1 & 2.1 & 31.3 & 159 & 18.6 & 5.9 & 34.4 & 5.0 & $<0.001$ & 0.200 & $<0.001$ & 0.385 & $<0.001$ & 0.00 \\
\hline $\mathrm{HR}_{\mathrm{av}}$ during BEFT (b.p.m.) ${ }^{3}$ & 41 & 178 & 138 & 204 & 56 & 189 & 166 & 210 & 11 & $<0.001$ & 0.241 & 0.163 & 0.612 & 0.001 & 0.27 \\
\hline $\mathrm{HR}_{\text {peak }}$ in BEFT (b.p.m.) ${ }^{4}$ & 41 & 225 & 195 & 238 & 56 & 224 & 203 & 237 & 8 & 0.773 & 0.073 & 0.108 & 0.915 & 0.185 & 0.56 \\
\hline $\mathrm{HR}_{\min }$ in BEFT (b.p.m. $)^{5}$ & 41 & 115 & 95 & 142 & 56 & 125 & 81 & 154 & 13 & 0.001 & 0.288 & 0.791 & 0.463 & 0.001 & 0.45 \\
\hline HR at end of BEFT (b.p.n & 41 & 194 & 123 & 229 & 56 & 203 & 136 & 229 & 21 & 0.067 & 0.152 & 0.608 & 0.248 & 0.022 & 0.178 \\
\hline HR 5 min recover & 62 & 108 & 69 & 137 & 114 & 115 & 87 & 136 & 9 & 0.001 & 0.687 & 0.003 & 0.079 & 0.001 & 0.312 \\
\hline HR 5th min of recovery (b.p.m.) ${ }^{7}$ & 73 & 90 & 49 & 124 & 142 & 96 & 74 & 119 & 9 & $<0.001$ & 0.745 & 0.002 & 0.060 & 0.001 & 0.16 \\
\hline
\end{tabular}

$\mathrm{RR}=$ respiratory rate; $\mathrm{RT}=$ rectal temperature; $\mathrm{Hb}=$ Haemoglobin; $\mathrm{TPP}=$ total plasma protein; $\mathrm{CK}=$ plasma creatine kinase; $\mathrm{AST}=$ plasma aspartate amino transferase; Lac $=$ plasma lactate.

${ }_{1}^{1}$ Values presented as least square means (mean) and root mean standard error (RMSE) and minimum (min) and maximum (max) values.

${ }^{2}$ The ratio of rider BW (riding tack not included) to horse BW.

${ }^{3}$ Average HR during BEFT.

${ }^{4}$ Peak HR in BEFT.

${ }^{5}$ Minimum HR in BEFT.

${ }^{6}$ Average HR during the first 5 min of recovery after the BEFT.

${ }^{7}$ Average HR during the 5 th minute of recovery after the BEFT.

There was a tendency for 4-year-old horses to be ridden a shorter distance in the BEFT than $5-, 6$ - and $\geqslant 7$-year-olds ( 2.7 v. $2.8,2.9,2.9 \mathrm{~km}, \mathrm{RMSE}=0.3, P=0.06)$, for a shorter duration (9:12 v. 9:35, 9:48 and 9:53 min:s, RMSE $=1.06$, $P=0.05)$ and at lower peak velocity $(40.7 v .42 .5,42.6,42.5$ $\mathrm{km} / \mathrm{h}, \mathrm{RMSE}=3.3, P=0.07$ ).

\section{Physiological responses to the BEFT}

Measured RR, RT, Htc, Hb, CK, AST and TPP increased following the BEFT $(P<0.001$; Table 3$)$. The HR during the BEFT was $184 \pm 13$ b.p.m. (range: 138 to 210 b.p.m., $n=102$ ) and during $36 \%$ of the BEFT HR was $\geqslant 200$ b.p.m., for $28 \%$ it was 180 to 199 b.p.m., for $15 \%$ it was 161 to 179 b.p.m. and for $21 \%$ it was $<160$ b.p.m. Peak HR during the BEFT was $224 \pm 9$ b.p.m. (range: 195 to 238 b.p.m., $n=102$ ). Mean HR as a proportion of peak HR during the BEFT was $82 \%$ (range: $64 \%$ to $90 \%$ ). The HR during the BEFT was affected by velocity $(P<0.001)$ and increased by 4 b.p.m. per $\mathrm{km} / \mathrm{h}$. Wind speed was positively correlated with the time when HR was $\geqslant 200$ b.p.m. in the BEFT $(r=0.25, P<0.05)$ The strongest wind speed was positively correlated with mean HR in the BEFT $(r=0.23, P<0.05)$ and with the time when HR was $\geqslant 200$ b.p.m. in the BEFT $(r=0.27, P<0.01)$.

Mean recovery HR during the 5 -min recording period was $113 \pm 10$ b.p.m. (range: 69 to 137 b.p.m., $n=187$ ) and HR during the last minute of the 5 -min recovery period was $95 \pm 10$ b.p.m. (range: 49 to 124 b.p.m., $n=228$ ). HR during the 5-min recovery period and HR during the last minute of that period were both affected by velocity $(P<0.001)$ and both increased by 2 b.p.m. per $\mathrm{km} / \mathrm{h}$. Horses with scores $\geqslant 5.5$ for pace had higher recovery HR during the 5 -min recovery period $(114 \pm 1$ v. $109 \pm 1$ b.p.m., $P<0.01)$ and during the last minute of the recovery period $(95 \pm 1$ v. $91 \pm 1$, $P<0.01)$.

Lac after the BEFT was $18.0 \pm 6.5 \mathrm{mmol} / \mathrm{l}$ (range: 2.1 to $34.4 \mathrm{mmol} / \mathrm{l}, n=266$ ) and $72 \%$ of the horses had Lac $\geqslant 15.0 \mathrm{mmol} / \mathrm{l}$ (range: 15.2 to $34.4 \mathrm{mmol} / \mathrm{l}), 15 \%$ had 10.0 to $14.9 \mathrm{mmol} / \mathrm{l}, 11 \%$ had 4.1 to $9.9 \mathrm{mmol} / \mathrm{l}$ and $2 \%$ had $\leqslant 4 \mathrm{mmol} / \mathrm{l}$. Velocity had an effect on $\operatorname{Lac}(P<0.001)$, with faster horses having higher values $(1.3 \mathrm{mmol} / /$ increase per $\mathrm{km} / \mathrm{h})$. The Lac after BEFT increased $(P<0.01)$ by $0.4 \mathrm{mmol} / \mathrm{l}$ for every $1 \%$ increase in BWR. Horses awarded a score $\geqslant 5.5$ 
for pace had higher Lac $(17.7 \pm 0.6$ v. $14.0 \pm 0.6 \mathrm{mmol} / \mathrm{l}$, $P<0.001)$ than horses that received no score $(=5.0)$ for pace.

The RR after the BEFT was affected by velocity (Table 3) and increased by five breaths $/ \mathrm{min}$ per $\mathrm{km} / \mathrm{h}$. RT was affected by distance (Table 3 ) and was $0.2^{\circ} \mathrm{C}$ higher per km covered in the BEFT. CK was affected by distance $(P<0.01)$ and was $114 \mathrm{U} / \mathrm{l}$ lower per $\mathrm{km}$ covered. $\mathrm{Hb}$ values after the BEFT increased by $0.8 \mathrm{~g} / \mathrm{l}$ per $1 \%$ increase in BWR.

\section{Effect of sex}

Stallions had lower RT than mares after the BEFT $(P<0.05)$ and higher $\mathrm{Htc}, \mathrm{Hb}$ and TPP both before and after the BEFT $(P<0.001$; Table 3). Stallions had lower mean and minimum $\mathrm{HR}$ during the BEFT, lower recovery HR during the 5-min recovery period and lower HR during the last minute of the 5 -min recovery period than mares $(P<0.001$; Table 3$)$. Stallions also had lower Lac than mares after the BEFT $(P<0.001$; Table 3$)$.

\section{Effects of age group}

Four-year-old horses had higher RR than 5-, 6- and $\geqslant 7$-yearold horses (117 v. 102, 97, 96 breaths/min, RMSE 28, $P<0.05)$ after the BEFT. The 4-year-old horses had lower Htc (45\% v. $46 \%, 46 \%, 47 \%$, RMSE $2, P<0.05$ ) and $\mathrm{Hb}$ values (161 v. 166, 168, $170 \mathrm{~g} / \mathrm{l}$, RMSE $10, P<0.01$ ) than $5-, 6$ and $\geqslant 7$-year-old horses after the BEFT. The 5-year-old horses had lower Htc (46\% v. 47\%, RMSE 2, $P<0.01)$ and $\mathrm{Hb}$ values $(166$ v. $170 \mathrm{~g} / \mathrm{l}, \mathrm{RMSE} 10, P<0.05)$ than the $\geqslant 7$-year-old horses after the BEFT.

\section{Judgement scores}

Stallions received higher scores than mares $(7.76$ v. 7.57, RMSE $=0.27, P<0.001)$ and 4-year-old horses received lower scores than the older age groups $(7.48$ v. $7.68,7.75$, 7.74 , RMSE $=0.27, P<0.01)$.

\section{Discussion}

\section{Intensity of the BEFT}

The physiological responses observed in our study confirmed that the BEFT is a high-intensity exercise. The high peak, average, average/peak HR and a high proportion of exercise performed at $\mathrm{HR} \geqslant 200$ b.p.m., as well as marked increases in RR, RT, Htc, Hb, TPP, plasma CK, AST and Lac, show that the work load was strenuous and that anaerobic energy metabolism was necessary. However, there was considerable individual variation in the physiological responses to the BEFT.

It can be speculated that the peak HR observed was the maximal $H R$, as it was comparable to the maximal $H R$ observed in racing Thoroughbreds (range: 204 to 241 b.p.m.; Krzywanek et al., 1970) and Standardbreds (range: 210 to 238 b.p.m.; Åsheim et al., 1970). The average HR (184 b.p.m.) during the BEFT was probably close to the lactate threshold (Persson, 1983) and, together with the amount of time spent at $H R \geqslant 200$ b.p.m. $\left(\sim 3^{1 / 2} \mathrm{~min}\right)$, explains why the horses had high Lac. The Lac after the BEFT $(18.0 \pm 6.5 \mathrm{mmol} / \mathrm{l})$ was similar to that observed in Standardbred horses after a race (15 to $43 \mathrm{mmol} / /$; Ronéus et al., 1999), in 'high goal' polo ponies after a training match $(18.7 \pm 5.4 \mathrm{mmol} /$; Ferraz et al., 2010) and in eventing horses after an advanced 3-day event $(19.1 \pm 4.2 \mathrm{mmol} / \mathrm{l} ;$ White et al., 1995). The variation in Lac in the present study could be explained mostly (36\%) by sex, age group, distance, velocity, BWR and pace, whereas rider accounted for $14 \%$ of the random variation. However, the variation might also be explained by differences in muscle fibre composition and fitness (Lovell and Rose, 1991), although our study did not assess those parameters. Unfortunately, we had limited information on the training background of the horses, but according to the riders most $(62 \%)$ horses were quite well prepared (preparation score $>7.0$ ). However, the only physiological parameter correlated $(r \geqslant 0.2, P<0.05)$ to the riders' opinion was minimum HR $(r=-0.25, P<0.05)$, which indicates that the riders' opinions were poorly reflected in the physiological responses. It is possible that the trainers did not have physical preparation in mind when answering the question about level of preparation, but rather preparation for showing gaits that score high according the judging scale (FEIF, 2002). However, few significant $(P<0.05)$ correlations between rider opinion and scores were found and the significant ones were weak. For example, there was a correlation between rider opinion and score for gallop $(r=0.21$, $P<0.001)$ and with form under rider $(r=0.18, P<0.01)$.

\section{Effect of sex}

There was a clear effect of sex in the response to the BEFT. Although stallions covered longer distances (warm-up plus BEFT) and performed at higher speed, they had lower HR and Lac. This indicates that aerobic fitness was higher in stallions than in mares, which is also supported by the higher Htc and $\mathrm{Hb}$ values. A higher $\mathrm{Htc}$ in Standardbred trotter stallions than in mares has been shown previously (Persson et al., 1996) and a higher $\mathrm{Hb}$ concentration has been found in stallions than mares of other breeds (Persson, 1967; Čebulj-Kadunc et al., 2002). A significant sex difference in the proportion of type IIB fibres in the gluteal muscle has been found in untrained 4 to 5-year-old Icelandic horses, with a higher proportion in mares than in geldings, $53.5 \%$ v. $44.4 \%$ (Henckel et al., 1994). In addition, all fibre types in geldings were surrounded by more capillaries than those found in mares (Henckel et al., 1994). A sex differences in fibre composition is also supported by findings in Thoroughbred and Standardbred horses, with stallions having a higher type IIA/ IIB ratio in $m$. gluteus medius than mares (Ronéus et al., 1991; Ronéus, 1993). Horses with higher oxidative capacity usually have higher type IIA/IIB ratio (Ronéus et al., 1992) and, taken together, this indicates that male Icelandic horses have higher oxidative capacity than mares. Our results confirm findings by Persson and Ullberg (1974) in Standardbred horses, where stallions were suggested to have higher aerobic capacity than mares and geldings and findings on 
Thoroughbred and Standardbred horses, where males are reported to be faster than females (Árnason, 2001; Mukai et al., 2003) and to have lower HR than females (Mukai et al., 2003). The difference in aerobic fitness observed between stallions and mares in the present study might of course also be owing to differences in training practices, but according to the riders stallions were not better prepared than mares (7.3 v. 7.2, RMSE 1.5 and $P=0.66$ ).

In human athletes, it is commonly accepted that there are gender differences such as greater muscle mass, muscle strength and aerobic capacity in males that contribute to superior performance (Lewis et al., 1986). Another reason for the superior performance observed in stallions in the present study might be lower body fat content compared with mares, as indicated by the lower BCS. In humans, it is known that body fat content is inversely related to both sprint and endurance running performance (Lewis et al.,1986) and similar observations have been made in horses (Kearns et al., 2002). There is no obvious explanation for the higher TPP observed in stallions, but they could have been more excited than mares and increased sympathetic activity can increase hydrostatic pressure and sweat losses, both of which could elevate TPP. Increased sympathetic activity in the stallions is also supported by their higher Htc before exercise. Training can also increase TPP (Fazio et al., 2011), but as earlier mentioned stallions were, according to the riders, not better prepared than mares.

\section{Effects of age group}

The 4-year-old horses had lower $\mathrm{Htc}$ and $\mathrm{Hb}$ values and higher post-exercise RR than the older horses, although they were ridden a shorter distance, for a shorter duration and at lower peak velocity $(P<0.1)$. This indicates less aerobic capacity and might be a reason for the riders consciously spared their performance. The lower Htc values are in accordance with previous findings on Standardbred horses in training, where the Htc has been shown to increase up to 4 and 5 years in mares and stallions, respectively (Persson et al., 1996). In the present study, $\mathrm{Hb}$ and Htc increased numerically up to $\geqslant 7$ years of age, indicating that fitness was improved. However, if an increase in age is associated with a more experienced and better-trained horse, more signs of improved fitness could be expected (e.g. reduced HR). The lack of such signs might indicate that the general level of fitness in this population was not improved much after 5 years of age. However, it is also likely that there were more horses in the older age groups that were less talented and might have spent more energy on showing good gaits.

\section{Effect of velocity and distance}

As could be expected, velocity during the BEFT had a significant effect on several physiological parameters. It affected post-exercise Lac, exercise and post-exercise HR, and postexercise RR, all of which increased with increased velocity. The higher the velocity, the more fibre types recruited and recruitment of type II fibres, particularly IIB, results in lactate production (Snow and Valberg, 1994). The effect of velocity on AST both before and after exercise could be related to common training practices and higher fitness in faster horses (Fazio et al., 2011).

The distance covered seemed only to affect post-exercise RT and CK concentration. Similarly, Hodgson et al. (1993) showed a linear increase in RT with time and workload. The plasma activity of CK can reflect cell membrane permeability, which could be fatigue dependent (Anderson, 1975). Interestingly, the concentration of CK was lower as the horses were ridden a longer distance, although duration of exercise has been suggested to be an even more important factor than intensity for the release of CK during exercise (Anderson, 1975). Possible explanations could be that fitter horses were ridden longer and/or that horses with higher CK concentrations were not ridden longer because the riders perceived these horses to be already tired. It has been suggested that the higher response of glycolytic metabolism might be reflected in higher values of CK and AST because of permeability changes in muscle fibre membranes (Fazio et al., 2011). CK and AST levels may also be affected by concentrate intake (Ribeiro et al., 2004) and transportation time (Leadon et al., 1989); however, in the present study, no correlations were found between these enzymes and diet and transport time (data not shown).

The distance covered during a BEFT should be 1.8 to $3.0 \mathrm{~km}$ (6 to 10 times of maximum $300 \mathrm{~m}$ each). In the present study, only $20 \%$ of horses were ridden $<2.5 \mathrm{~km}$ and $41 \%$ were ridden $\geqslant 3.0 \mathrm{~km}$, which indicates that many riders do not comply with the BEFT instructions.

\section{Effect of pace}

Flying pace is a high-speed gait in the BEFT (velocity can reach around 30 to $40 \mathrm{~km} / \mathrm{h}$ ) and horses showing pace not only covered a longer distance but also at a higher average speed. Pace is also a gait likely to increase energy expenditure compared with the most economical gait at this velocity gallop. It has been found that ponies appear to choose a gait that maximises energy efficiency and that if they are forced to use extended gaits the $\mathrm{VO}_{2}$ can increase by up to $70 \%$ (Hoyt and Taylor, 1981). Altogether this may explain why horses that showed the pace gait had significantly higher Lac and recovery HR than horses not showing pace.

\section{Scores}

We believe that the horses participating in this study were representative of the population of Icelandic horses attending a BEFT, as there was no difference in total score for riding abilities between horses participating in the study compared with non-study horses. According to Árnason (1984, Porvaldur Árnason personal communication, 2013), age is important for scores and an increase in total score (conformation and riding abilities) can be expected yearly from 4 to 7 years old. In the present study, we compared the total score for riding abilities, for which 4-year-old horses had lower scores than older horses. 
Weather and correlations with physiological parameters Because of the low ambient temperature, low humidity and windy conditions, heat loss through conduction, convection and evaporation was facilitated. It has long been known that air resistance increases energy expenditure during running and walking in humans (Pugh, 1971), and interestingly in the present study, HR increased as wind speed increased. Actually a few riders decided not to finish the BEFT (horses excluded from the study) because of the strong wind speed (the day with mean $12.9 \mathrm{~m} / \mathrm{s}$ ).

\section{Conclusions}

This study showed that the riding assessment in a BEFT is a high-intensity exercise and maybe even, for some horses, supramaximal exercise. The study also showed that aerobic fitness was higher in stallions and that age had a limited effect on the physiological response. These results should be used as a guide for the development of training programmes and fitness tests in Icelandic horses that would improve both performance and welfare of the horses.

\section{Acknowledgements}

The authors sincerely thank the riders, riders' assistants, owners of horses and staff at the BEFT at Hella between 30 May and 9 June 2011 for their collaboration. Special thanks to the research team at Hella; Eggert Gunnarsson at Keldur, Heiða Sigurðardóttir, Johanna Karin Knutsson, Pieter de Gouw, Rósa Kristinsdóttir and Sigríður Ólafsdóttir. Thanks to Anna Greta Haglund for analyses of the plasma lactate and Claudia von Brömssen for statistical advice, both at the Swedish University of Agricultural Sciences. Thanks to the Institute for Experimental Pathology at Keldur University of Iceland, the Farmers Association in Iceland, the Horse Breeders Association in Iceland, the horse breeding advisor Guðlaugur Antonsson and the head of the Horse Breeding Council Kristinn Guðnason for their support and help. The project was funded by Developmental Fund of the Icelandic Horse Breeding, the Pálmi Jónsson Natural Conservation Fund and the Stock Protection Fund of the Icelandic Horse breed.

\section{References}

Anderson MG 1975. The influence of exercise on serum enzyme levels in the horse. Equine Veterinary Journal 7, 160-165.

Árnason T 1984. Genetic studies on conformation and performance of Icelandic toelter horses. IV. Best linear unbiased prediction of ten correlated traits by use of an 'Animal Model'. Acta Agriculturae Scandinavica 34, 450-462.

Árnason T 2001. Trends and asymptotic limits for racing speed in Standardbred trotters. Livestock Production Science 72, 135-145.

Åsheim A, Knudsen O, Lindholm A, Rülcker C and Saltin B 1970. Heart rates and blood lactate concentrations of Standardbred horses during training and racing. Journal of the American Veterinary Medical Association 157, 304-312.

Buttram ST, Willham RL and Wilson DE 1988. Genetics of racing peformance in the American Quarter Horse: II Adjustment factors and contemporary groups. Journal of Animal Science 66, 2800-2807.
Čebulj-Kadunc N, Božič M, Kosec M and Cestnik V 2002. The influence of age and gender on haematological parameters in Lipizzan horses. Journal of Veterinary Medicine Series A 49, 217-221.

Fazio F, Assenza A, Tosto F, Casella S, Piccione G and Caola G 2011. Training and haematochemical profile in Thoroughbreds and Standardbreds: a longitudinal study. Livestock Science 141, 221-226.

Ferraz GC, Soares OAB, Foz NSB, Pereira MC and Queiroz-Neto A 2010. The workload and plasma ion concentration in a training match session of high-goal (elite) polo ponies. Equine Veterinary Journal 42 (suppl. 38), 191-195.

Henckel P, Ducro B and Sveinsson I 1994. Muscle histochemical profile of the Icelandic horse. Age and sex differences (abstract). Livestock Production Science 40, 78-79.

Hodgson DR, McCutcheon LJ, Byrd SK, Brown WS, Bayly WM, Brengelmann GL and Gollnick PD 1993. Dissipation of metabolic heat in the horse during exercise. Journal of Applied Physiology 74, 1161-1170.

Hoyt DF and Taylor CR 1981. Gait and the energetics of locomotion in horses. Nature 292, 239-240.

International Federation of Icelandic Horse Associations (FEIF) 2002. FEIF rules for Icelandic Horse Breeding (FIZO 2012). Retrieved April 16, 2013, from http:// www.feiffengur.com/documents/fizo12e.pdf

International Federation of Icelandic Horse Associations (FEIF) 2013. News, facts and figures. Retrieved April 16, 2013, from http://www.feif.org/FEIF/ Factsandfigures/tabid/497/Default.aspx

Kearns CF, McKeever KH, Kumagai K and Abe T 2002. Fat-free mass is related to one-mile race performance in elite Standardbred horses. The Veterinary Journal $163,260-266$.

Krzywanek H, Wittke G, Bayer A and Borman P 1970. The heart rates of Thoroughbred horses during a race. Equine Veterinary Journal 2, 115-117.

Leadon D, Frank C and Backhouse W 1989. A preliminary report on studies on equine transit stress. Journal of Equine Veterinary Science 9, 200-202.

Lewis DA, Kamon E and Hodgson JL 1986. Physiological differences between genders. Implications for sports conditioning, review. Sports Medicine 3, 357-369. Lovell DK and Rose RJ 1991. Changes in skeletal muscle composition in response to interval and high intensity training. In Equine exercise physiology. Proceedings of the 3rd International Conference (ed. SGB Persson, A Lindholm and LB Jeffcott), pp. 215-222. ICEEP Publications, Davis, California, USA.

Mukai K, Takahashi T, Hada T, Eto D, Kusano K, Yokota S, Hiraga A and Ishida N 2003. Influence of gender and racing performance on heart rates during submaximal exercise in Thoroughbred racehorses. Journal of Equine Science 14, 93-96.

Persson SGB 1967. On blood volume and working capacity in horses. Acta Veterinaria Scandinavica suppl. 19, 101-121.

Persson SGB 1983. Analysis of fitness and state of training: evaluation of exercise tolerance and fitness in the performance horse. In Equine exercise physiology. Proceedings of the 1st International Conference (ed. DH Snow, SGB Persson and RJ Rose), pp. 441-457. Granta Publications, Cambridge, UK.

Persson SGB 1997. Heart rate and blood lactate responses to submaximal treadmill exercise in the normally performing Standardbred Trotter - age and sex variations and predictability from the total red blood cell volume. Journal of Veterinary Medicine Series A 44, 125-132.

Persson SGB and Ullberg LE 1974. Blood volume in relation to exercise tolerance in trotters. Journal of the South African Veterinary Association 45, 293-299.

Persson SGB, Funkquist P and Nyman G 1996. Total blood volume in the normally performing Standardbred Trotter: age and sex variations. Journal of Veterinary Medicine Series A 43, 57-64.

Pugh LG 1971. The influence of wind resistance in running and walking and the mechanical efficiency of work against horizontal or vertical forces. The Journal of Physiology 213, 255-276.

Ribeiro WP, Valberg SP, Pagan JD and Essén-Gustavsson B 2004. The effect of varying dietary starch and fat content on serum creatine kinase activity and substrate availability in equine polysaccharide storage myopathy. Journal of Veterinary Internal Medicine 18, 887-894.

Ronéus M 1993. Muscle characteristics in Standardbreds of different ages and sexes. Equine Veterinary Journal 25, 143-146.

Ronéus $M$, Lindholm $A$ and Åsheim $\AA$ 1991. Muscle characteristics in Thoroughbreds of different ages and sexes. Equine Veterinary Journal 23, 207-210. 
Ronéus M, Essén-Gustavsson B, Lindholm A and Persson SGB 1992. Skeletal muscle characteristics in young trained and untrained Standardbred trotters. Equine Veterinary Journal 24, 292-294.

Ronéus N, Essén-Gustavsson B, Lindholm A and Persson S 1999. Muscle characteristics and plasma lactate and ammonia response after racing in Standardbred trotters: relation to performance. Equine Veterinary Journal 31, 170-173.

Seeherman HJ and Morris EA 1991. Comparison of yearling, two-year-old and adult Thoroughbreds using a standardized exercise test. Equine Veterinary Journal 23, 175-184.
Snow DH and Valberg SJ 1994. Muscle anatomy, physiology and adaptations to exercise and training. In The athletic horse (ed. DR Hodgson and RJ Rose), pp. 145-179. WB Saunders, USA.

Stefánsdóttir GJ and Björnsdóttir S 2001. Body condition scoring of horses (Mat á holdafari hrossa), special issue. Eiðfaxi-Ræktun, pp. 60-65.

White SL, Williamson LH, Maykuth P, Cole S and Andrews F 1995. Heart rate and lactate concentration during two different cross country events. Equine Veterinary Journal 27 (suppl. 18), 463-467.

WorldFengur 2013. The studbook of origin for the Icelandic horse. Retrieved March 25, 2013, from www.worldfengur.com 